\title{
Methods for Expressing the Category of Approximation in Russian in Comparison with Its Equivalents in Persian
}

\section{Hasanzadeh Rezvan ${ }^{1}$}

Assistant Professor at the Department of Russian and Slavic Languages and Literatures, Faculty of Literature and Humanities, Shahid Beheshti University

Tehran, Iran.

(date of receiving: July, 2020; date of acceptance: January, 2021)

\begin{abstract}
The main topic of this article is devoted to the study of the ways of expressing the category of approximate relations in Russian in comparison with its equivalents in Persian. The article studies the linguistic means of expressing approximate (approximate) values that are common in both languages in various communicative spheres of communication. The novelty of this study lies in the fact that for the first time it compares the means that in their semantics contain the meanings of the category of approximation in the Russian language in comparison with its equivalents in the Persian language. The research object of this article was the Russian and Persian language means expressing the semantics of approximate relations in various communicative spheres. The results of this study can be useful not only for students who study Russian as a foreign language in an Iranian audience, but also for Russian-speaking students who study Persian as a foreign language. In the course of the work, descriptive and comparative-comparative methods are used.
\end{abstract}

Keywords: Quantity, Category of Approximation, Quantitative Semantics, Russian, Persian, Comparative Analysis.

1. E-mail: re hassanzadeh@sbu.ac.ir 


\title{
Способы выражения категории аппроксимативности в русском языке в сопоставлении с ее эквивалентами в персидском языке
}

\section{Хасан-заде Резван ${ }^{1}$}

Преподаватель кафедры русского языка и литературы и славянских языков, Университет им. Шахида Бехешти,

Тегеран, Иран.

(дата получения: июль 2020 г.; дата принятия: январь 2021 г.)

\begin{abstract}
Аннотация
Тема данной статьи посвящена изучению способов выражения категории приблизительных отношений в русском языке в сопоставлении с ее эквивалентами в персидском языке. В ней изучены языковые средства выражения аппроксимативных (приблизительных) значений, которые распространены в обоих языках в различных коммуникативных сферах общения. Новизна данного исследования заключается в том, что в нем впервые сопоставляются средства, которые в своей семантике содержат значения категории аппроксимативности в русском языке в сопоставлении с ее эквивалентами в персидском языке. Объектом исследования данной статьи послужили русские и персидские языковые средства, выражающие семантику приблизительных отношений в различных коммуникативных сферах. Результаты данного исследования могут быть полезными не только студентам, которые изучают русский язык как иностранный в иранской аудитории, но и русскоговорящим учащимся, изучающим персидский язык как иностранный. В ходе выполнения работы используются описательный и сравнительно-сопоставительный методы.
\end{abstract}

Ключевые слова: Количество, Категория Аппроксимативности, Количественная Семантика, Русский Язык, Персидский Язык, Сопоставительный Анализ.

1. E-mail: re_hassanzadeh@sbu.ac.ir 


\section{Введение}

Одной из особенностей, которые вызывают большой интерес для иранской аудитории, являются языковые средства, т.е. слова или сочетания слов, с помощью которых выражается категория количества в русском языке, а в частности категория приблизительных отношений.

Цель данной статьи состоит в том, чтобы, ссылаясь на языковой материал двух языков, охарактеризовать и проанализировать особенности языковых средств, которые отражают семантику категории аппроксимативности (приблизительности). Результаты данного исследования могут быть полезными не только для студентов, изучающих РКИ в иранской аудитории, но и для русскоговорящих учащихся персидскому языку как иностранному, так как коммуникативные потребности учащихся, желание научиться хорошо владеть русским или персидским языками зримо ощущается со стороны учащихся как в иранской, так и российской аудиториях. В данной работе используются описательный и сравнительно-сопоставительный методы.

\section{Основная часть}

Одним из немаловажных вопросов, который интересует многих лингвистов, является категория количества. Данная тема была изучена в научных работах различных лингвистов, таких как А. А. Реформатский, О. Х. Есперсен, Т. Тошович, Л. Е. Кругликова, 3. Я. Тураева, А. А. Холодович, Т. П. Ломтев, Е. Д. Панфилов, М. А. Кумахов, О. С. Чеснокова, Г. Г. Галич, К. Ч. Полянский, В. В. Акуленко, Г. А. Меновщиков, С. А. Жаботинская, и т.д. Все они сходятся во мнении, что познание человеком количества и количественных отношений неразрывно связано с развитием языковых форм. Так, А.А. Реформатский считал, что «язык, отражая мышление, включает и достижение ума человека - число» (Реформатский 1987. 76). 
Однако данная тема все еще остается не до конца изученной, и многие лингвисты все еще спорят по разным вопросам определения сущности данной категории, ее классификации, признаков, а также языковых средств ее выражения.

В свою же очередь, О. Х. Есперсен относительно категории количества отмечал, что категория количества представляет собой языковую систему, которая включает в себя свойства объективной действительности. (Есперсен 1958. 57) Подобное мнение излагалось в изучении истории философии и Аристотелем, и Декартом, и даже Гегелем (Реформатский 1987. 77)

Г.Г.Галич в своей книге «Когнитивная категория количества» относительно данной категории пишет следующее: «Под понятием количество нужно подразумевать всякий исчисляемый или измеряемый признак». (Галич 2002. 26-27) Иными словами, человеческое мышление устроено таким образом, что помимо качественных признаков предметов, состояний, действий, признаков действий, оно еще замечает и количественные признаки, наблюдаемые в окружающем мире, и поэтому во всех языках мира почти на всех языковых уровнях существуют определенные языковые средства, выражающие те или иные количественные признаки. Каждый языковой уровень образует определенную систему, соотносящуюся с категорией количества. Иначе говоря, каждый уровень того или иного языка обладает рядом средств, выражающих ту или иную количественную семантику. Изучение данного вопроса в русском языке показывает, что данный язык на разных языковых уровнях обладает богатым набором средств, выражающих значения количественной категории.

На фонетическом уровне самым распространенным средством выражения категории количества являются просодия и ударение. Например, Смотрите, дли-инный какой поезд! Здесь просодия и произношение усиливают качественную характеристику высказывания, придавая ей отчетливо выраженную количественную, т.е. очень длинный поезд. 
На морфологическом уровне данная категория может выражаться рядом морфем, указывающих на количественную характеристику высказывания, например много-, мало-, мульти-, морфологическими категориями, такими как лицо, время, вид и числа, степени сравнения. (Мечковская 2005. 449-452)

На словообразовательном (деривационном) уровне данная категория может выражаться словообразовательными способами, которые выражают уменьшение и увеличение того или иного признака: дом - домище; дом домик.

На лексическом уровне существует множество лексических средств, обозначающих как количественную, так и качественно-количественную семантику. Это такие лексико-семантические группы слов, которые могут указывать на число: один, два, три, мало, много, всё, весь, и т.п. либо на атрибутивную характеристику предметов, как большой, маленький, либо слова, которые могут усиливать степень проявления того или признака предмета или действия: очень, больше, либо слова, обладающие семантикой временной и пространственной характеристики: всегда, долго, недолго, одно время, далеко, вблизи и т.д. (Вежбицкая 1999. 10)

На синтаксическом уровне также рассматриваются такие средства выражения категории количества, как инверсия, изменение порядка слов, повтор и удвоение слов в предложениях: штук пять, день за днем, черный черный, иду-иду. (Маслов 2004. 305-364)

В русском языке количественная семантика может наблюдаться и при выражении модально-субъективных значений. Как правило, она выражается модально-оценочными словами, которые обозначают степень вероятности описываемого события. Это такие вводные слова, как вероятно, наверное, может быть, непременно и т.п. (Беляева 1990. 163-166)

Классификация категории количества, выраженного языковыми средствами, представляет собой один из самых сложных вопросов. Причиной 
тому служит то, что количество очень сложное и многоаспектное понятие, которое в силу своей сущности обладает различными признаками и отношениями. В русском языке выделяются следующие подгруппы в классификации категории количества: это единичность и множественность, точность и приблизительность, определенность и неопределенность, расчлененность и нерасчлененность, кардинальность и ординальность, суммарность и дистрибутивность, упорядоченность и неупорядоченность, дискретность и непрерьвность, экстенсивность и интенсивность, отношения «больше»- «меньше» (Тошович 2005. 120)

Итак, как уже было сказано ранее, одной из подгрупп категории количественных отношений в русском языке является выражение аппроксимативного (приблизительного) количества, которое противопоставляется выражению точного количества, и как отмечает Бодуэн де Куртенэ, значения аппроксимативности могут выражаться с помощью целого ряда языковых средств, а также применяться и по отношению к времени и к пространству (Бодуэн де Куртенэ 1963. 313)

Категорию приблизительного количества следует отличать от категории неопределенного количества. Категория неопределенного количества в плане содержания несет признаки только неопределенного количества чего-нибудь, тогда как категория аппроксимативности одновременно состоит из признаков, указывающих на неопределенность, и признаков, выражающих определенное количество чего-нибудь (Чеснокова 1997. 9). Вышеуказанное отличие можно заметить в семантике следующих словосочетаний: несколько студентов ( جند

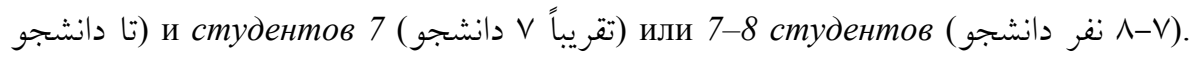
Как видно, в первом словосочетании выражается исключительно значение категории количественной неопределенности, а во втором и третьем примерах говорящий, прибегнув к употреблению языковых средств категории приблизительности, одновременно указывает на то, что установить точное 
число объектов невозможно, хотя приблизительно указывает на определенное количество объектов и утверждает, что их было 7 или 7-8 человек.

В ходе исследования нами были установлены следующие основные способы выражения категории аппроксимативности в русском языке. Далее все эти способы будут рассмотрены в сопоставлении с их эквивалентами в персидском языке.

Одним из самых распространенных языковых средств выражения категории аппроксимативности являются наречия, такие как почти, примерно приблизительно, приближенно, предположительно, где-то. Подобные наречия представляют собой лексические средства выражения количественной приблизительности в русском языке. Они как правило, выражают приблизительность проявления того или иного количественного признака в высказывании. Рассмотрим следующие примеры: Он приезжает $к$ нам примерно через неделю... (او حدوداً يك هفته ديخر بيش ما مى آيد.) Прошел почти год с того дня, как он сделал мне предложение. (تقريباً يك سال از روزى كه او به ماله Приблизительно за один-два месяца мы

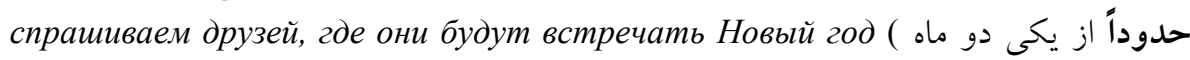

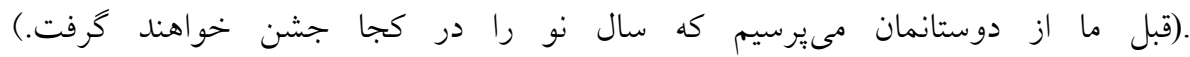

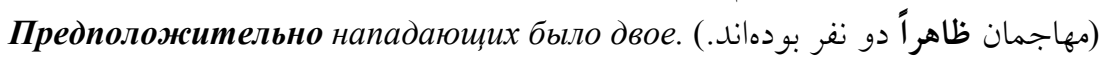

В персидском же языке эквивалентами подобных наречий являются такие же наречия с приближенным к ним семантическим значением. Это такие наречия как حدوداً - تقريباً - ظاهراً. Однако данные наречия, несмотря на то, что уже вошли в персидскую речь и довольно часто употребляются в речи персоговорящих, все же являются заимствованными словами, обладающими формой арабского языка, поэтому в целях пуризма языка рекомендуется употреблять в речи следующую синонимичную форму: حدود. Например, в первом случае вместо слова حدوداً, можно употребить слово او حدوداً يك :حدود :حدود :حود هفته ديخر بيش ما مى آيد заимствованным из арабского языка, но все же не имеет в конце слова 
компонента, так называемого нунациией или танвином, который является грамматическим средством выражения грамматических значений в арабском языке, и является более приемлемой формой с точки зрения иранских лингвистов и грамматистов.

В русском языке помимо наречий также существует целый ряд предлогов, которые также лексически могут указывать на значение количественной приблизительности, начальной и конечной границы отсчета. Это такие предлоги, как около, за, $c, \kappa$, под, до, порядка: Ему было уже далеко за сорок او كمتر از شصت ) (او جهل و خردهاى سال سن داشت.) Бй было под шестьдесят تقريباً يك ساعت بعد او با من ); Пالش بود.

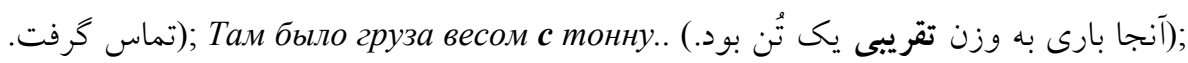

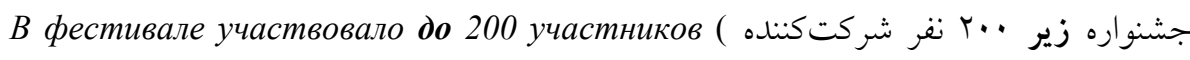
(داشت. К вечеру пошел сильный снег (حوالى عصر برف سنخينى گرفت).

В персидском языке также существует ряд предлогов и слов, которые могут выражать эквивалентную семантику соотнесенных предлогов русского языка. Результаты сопоставительного анализа эквивалентов приблизительного количественного значения в персидском языке показывает, что эквивалентом предлога около в персидском языке может служить слово نزديك - حدوداً - تقريباً. Эквивалентом выражения приблизительного значения при помощи предлога за в персидском языке являются следующие конструкции и сочетания слов « ...

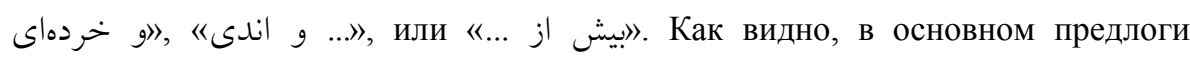
русского языка, выражающие приблизительное значение, могут переводиться на персидский язык при помощи таких эквивалентных выражений, как بيش از ... или .... و اندى -... و خردهاى - نزديك - تا - حدوداً.

Анализ вышеперечисленных предлогов, и образованных от них предложнопадежных форм показывает, что данные формы в русском языке выражают приблизительно-количественное значение, связанное с количеством предметов, возрастом лиц, и температуры (Золотова 1988. 220). 
Данные предлоги, в свою очередь, могут сочетаться и со словами, обозначающими фазисное значение: начало, конец, середина, которые также дают приблизительную временную характеристику (середина зимы, начало месяца, конец лета, середина шестидесятых и т.д.), а также могут при себе иметь такие выражения как с лишком, с небольшим, с гаком, которые выражают значение: немного больше предполагаемого количества. Например: Александру Владимировичу восемьдесят с гаком (آلكساندر واسيليويج هشتاد سال و نينا نسبت به (اندى سن دارد); Нина выглядит младше своих сорока с небольшим

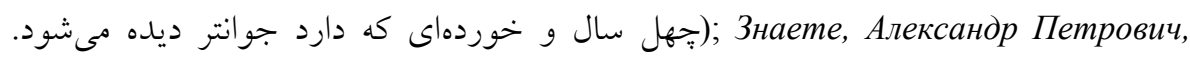
уже прошло шесть часов с лишком! ( مىدانيد آقاى آلكساندر يتراويج، شش و ساعت (و خوردهاى كذشته است.

Сопоставительный анализ показывает, что эквивалентными средствами выражения приблизительных значений в персидском языке являются такие

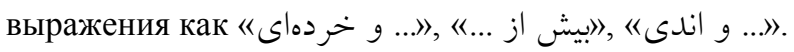

В русском языке для указания на меньшее, чем называемое, количество, используется отрицание. Сравним следующие примеры: Маме пятьдесят лет. Маме нет пятидесяти. Маме еще не было пятидесяти (مادر پنجاه سال سن دارد. (مادر زير ينجاه سال سن دارد. مادر كمتر از ينجاه سال سن داشت. Вовка влюбился в Настю, когда ему не исполнилось и двадцати лет. (وُوكا هنوز بيست سالش نشده (بود كه عاشق ناستيا شد.)

Как видно, в персидском языке для выражения подобных приблизительных количественных отношений могут употребляться такие конструкции, как 《....ري и безличная спряженная форма сложного глагола 《دوده نشالش نش....

А для приблизительного выражения временного или пространственного интервала в русском языке, как правило, употребляются предлоги om и до: om (+ Р.п.) до (+ Р.п). Например: Mы проведем в командировке от трех до пяти дней (مأموريت ما سه تا بنج روز طول خواهد كشيد); Допустимые значения температуры воздуха составляют от двадиати до сорока градусов. (دماى (هواى مجاز بين بيست تا جهل درجه است 
Сопоставительный анализ эквивалентных средств выражения данных приблизительных значений показывает, что в персидском языке для выражения приблизительного временного или пространственного интервала

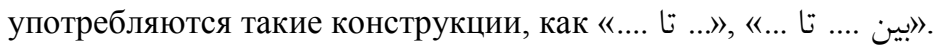

Для выражения верхнего или нижнего предела интервала со значением приблизительности могут использоваться слова: максимум или минимум. Например: Он вернется из командировки минимум через две недели, максимум через пять недель ( او حداقل دو هفته و حداكثر ينج هفته ى ديخر از (مأموريت برخواهد كشت (1) Мы сможем выполнить этот проект минимум за два месяиа, максимум за четыре месяия. (ما اين يروزه را دست كم ظرف دو ماه، و نهايتاً (ظرف جهار ماه مى توانيم انجام دهيم.

В персидском языке для выражения данного приблизительного значения можно также использовать средства, выражающие временной интервал: $M b l$ сможем выполнить этот проект минимум за два месяца, максимум за четыре месяиа..(ما قادر به انجام اين بروزه در مدت زمان دو تا جهار ماه هستيم.)

Данное значение также можно выразить теми же лексическими языковыми средствами, что и в русском языке: ما قادر به انجام اين گيروزه در مدت زمان حداقل دو ماه و حداكثر تجهار ماه هستيم.

В русском языке также могут употребляться слова свыше, более, больше или менее и меньше. Они, как правило, употребляются для выражения несовпадения указываемого количества объектов. Рассмотрим следующие примеры: Прошло более месяиа, но о его судьбе мы ничего не знали (بي از يك (ماه كذشته بود، ولى ما جيزى در مورد سرنوشتش نمى دانستيم. Нама поездка в Исфаган заняла более двух недель (سفر ما به شهر اصفهان بيش از دو هفته به طول انجاميد.); B Москве Андрей провел менее месяйа (آندرى كمتر از يك ماه در مسكو بود.); Этому историческому памятнику уже свыме шестисот лет. (قدمت اين بناى تاريخى به (بيش از ششصد سال مىرسد. 
Как видно из рассмотренного примера, в основном эквивалентами данных

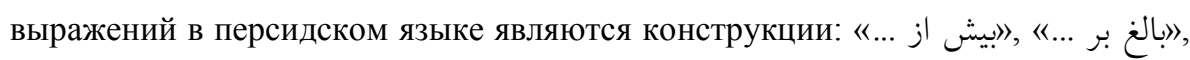
«... اكمتر إن.

Также для выражения приблизительно-количественного значения в русском языке может использоваться слово пара. Необходимо учитывать, что данное слово употребляется в разговорном стиле речи. Рассмотрим следующие примеры: Можно прийти к тебе на пару минут? ( ميشه براى يكى دو دقيقه مزاحمت بشوم؟); Необходимо воспользоваться случаем, и сказать пару слов о вамей работе (مخايد از فرصت استفاده كرد و كمى (مختص، دو كلمه) در مورد ) (كارتان صحبت كرد.

Урысон в своей книге применительно к этому слову отмечает, что слово napa обозначает приблизительность, и говорящий при его употреблении вовсе не констатирует и не выражает точность. Сравните употребление этого слово в следующих высказываниях: Побудь еще здесь пару дней, а потом примем другое ремение ( يكى دو روز ديخر (جند روزى) اينجا بمان، بعدش تصميم ديخرى

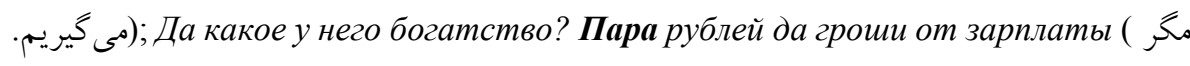
او ثروتى هم دارد؟ تمام ثروتش جند روبلى است با جندرغازى كه از حقوقش دريافت مى كند. (Урысон 1997. 67).

Сопоставительный анализ эквивалентных средств выражения данных приблизительных значений показывает, что в персидском языке для выражения данной приблизительной семантики употребляются такие

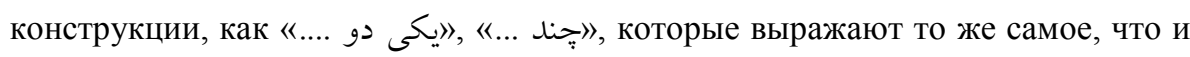
слово пара в русском языке.

В русском языке следующим языковым средством выражения аппроксимативного значения является разговорная и просторечная конструкция, комбинирующая в своем составе как и пространственные так и временные компоненты: где-то в районе, и выражает приблизительную временную характеристику. Рассмотрим следующий пример: Mbl договорились 
увидеться где-то в районе трех (حا قرار گذاشتيم حوالى (حول و حوش) ساعت سه (همديخر را ببينيم.

Как видно из примеров, в основном эквивалентами данных выражений в персидском языке являются выражения и словосочетания: 《ول و "...حو الى ... حوش а, а сопоставительный анализ эквивалентных средств выражения данных приблизительных значений показывает, что в персидском языке для выражения приблизительной семантики данного примера могут употребляются и такие конструкции, как 《... ما قرار كذاشتيم : ما قرار كذاشتيم سه نشده همديخر را ببينيم. زنزديك ساعت سه همديخر را ببينيم.

Также следует отметить, что в русском языке приблизительный интервал времени может выражаться при помощи конструкции «порядковое имя числительное во множественном числе + имена существительные со значением отрезка времени во множественном числе». Рассмотрим следующие примеры: В семидесятые годы он числился в розыске ( در سالfاى هفتاد او تحت تعقيب بود. Экономика в сороковые годы была совсем другой, чем

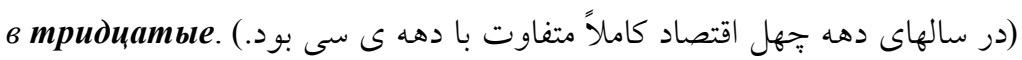

Как видно, в данных примерах форма множественного числа порядковых числительных и имен существительных значительно удаляется от своей семантики и обозначает приблизительный временной отрезок: словосочетание тридцатые годы равняется десятилетию и в нем выражается неопределенный и приблизительный временной отрезок, а в словосочетании тридиатый год выражается точное временное значение, т.е. 1930-й год (Есперсен 1958. 220). В таких конструкциях очень часто в разговорной речи имена существительные множественного числа могут и вовсе не употребляться (Чеснокова 1997. 125).

Сопоставительный анализ эквивалентных средств выражения данных приблизительных значений показывает, что в персидском языке для выражения подобной семантики могут употребляться следующие

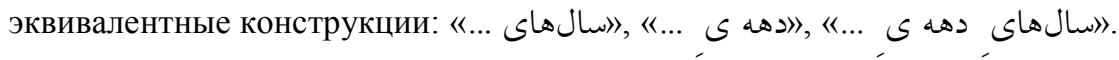


Следующим способом выражения аппроксимативности в русском языке является изменение порядка слов в словосочетаниях, состоящих из имени числительного и имени существительного. Данное явление в языкознании называется инверсией (Подлесская, Стародубцева 2013. 30). Далее рассмотрим следующие примеры: Ей было лет сорок (او تقريباً جهل سال سن داشت); Mbl

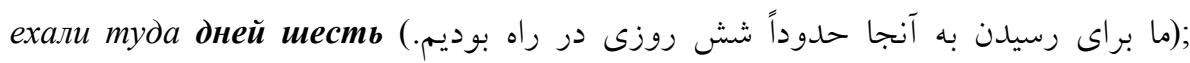

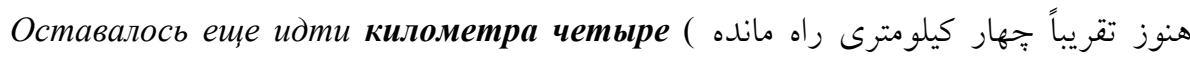
(بود.). В доме находилось человек пять, когда произошло данное происшествие (زمانى كه اين اتفاق رخ داد حدوداً جهار نفر در خانه بودند.). Как видно из примеров в подобных синтаксических конструкциях имя существительное, как правило, обозначает единицы измерения: день, год, километр, метр, штук, килограмм и т.д.

В персидском языке, по аналогии русскому языку приблизительность может выражаться и при помощи неопределенного артикля $\mathfrak{s}$, при этом существительное всегда стоит после числительного в неопределенной форме: شش درختى (примерно шесть деревьев), هشت پسرى (приблизительно восемь мальчиков), ينج كارگرى (около пяти рабочих) (Рубинчик 2001. 189).

Сопоставительный анализ эквивалентных средств выражения данных приблизительных значений показывает, что в персидском языке для выражения подобной семантики могут употребляться следующие

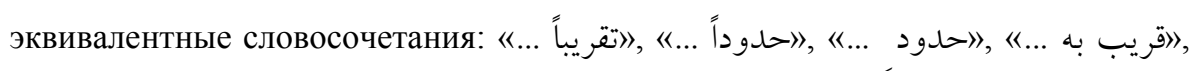
«... ات. Данные языковые средства в персидском языке выражают подобную приблизительную семантику. Однако их выбор в персидской речи определяется тем функциональным стилем речи, к которому они принадлежат.

В русском языке для выражения приблизительного количества может употребляться и комбинированный способ, включающий как инверсию, так и способ выражения с помощью предлогов с этим значением: Саще было лет за пятьдесяm (ساشا تقريباً پنجاه سال و خوردهاى سن داشت.); Собак с десяток сидело

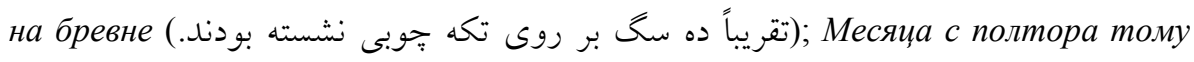


назад к нам в село приезжала делегащия из Москвы ) تقريباً (حدود) يك و نيم ماه (ييش هيأتى از مسكو به روستاى ما آمده بود. Сопоставительный анализ эквивалентных средств выражения данных приблизительных значений показывает, что в персидском языке для выражения подобной семантики употребляются те же самые языковые средства, которые были рассмотрены в данном разделе.

В подобных конструкциях также могут употребляться и выражения, обозначающие и усиливающие значения сомнения, неуверенности, неопределенности, и предположительности высказывания говорящим. Рассмотрим следующие примеры: Наверное, Саше было лет за пятьдесят (احتمالاً ساشا تقريباً ينجاه سال و خوردهاى سن داشت.); Может быть, месяиа c полтора тому назад к нам в село приезжала делегаџия из Москвы ( شايد تقريباً

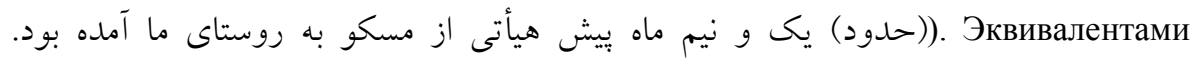
подобных языковых средств в персидском языке, как правило, являются:

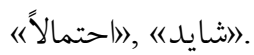

Другим способом выражения приблизительности в русском языке является использование сочинительного союза или же использование тире вместо него. Далее рассмотрим следующие примеры: $B$ ящике было пять или шесть арбузов (در جعبه تقريباً ينج يا شش عدد هندوانه وجود داشت) Он успел прихватить

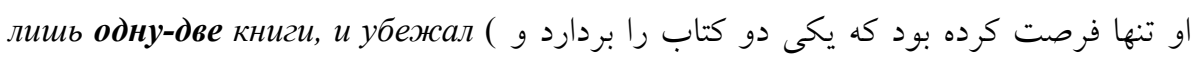
(سبس فرار كرد. В подобных конструкциях в русском языке также иногда могу употребляться и слова, такие как минус и плюс, которые в русском языке прибавляют к семантике высказывания значение аппроксимативности: Увидимся с тобою на площади Азади в десять утра, плюс-минус (حول و حوش (حوالى) ساعت •ا صبح در ميدان آزادى همديخر را مىبينيم. Сюда и могут входить такие сочетания слов, как максимум-минимум, которые были ранее рассмотрены: Иван определял свои планы максимум-минимум во имя действия (ايوان برنامهاى خود را كم و بيش در راستاى كار مىريخت). 
Сопоставительный анализ эквивалентных средств выражения данных приблизительных значений показывает, что в персидском языке для выражения подобной семантики могут употребляться следующие

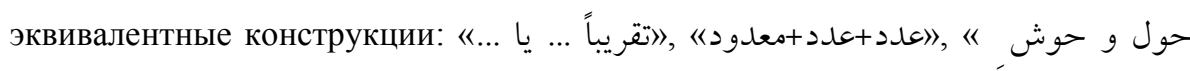
...», 《.... تقريباً ..."

В персидском языке для обозначения подобного приблизительного количества употребляются и подряд количественные числительные, сочетающиеся между собой путем примыкания: هفت (один-два дня رو دو (о) هشت ساعت (семь-восемь часов), سى جهل نف (тридцать-сорок человек).

Относительно таких сочетаний слов в русской устной речи Т.Е. Янко в своей книге излагает, что для произношения предложений с такими конструкциями используется особая интонация незавершенности (Янко 2008. 109).

Исходя из вышесказанного, можно сделать вывод, что для обозначения приблизительности в русском языке используются не только лексические и синтаксические языковые средства, но и просодические.

\section{Заключение}

Количественная приблизительность - эта языковая категория, значения которой выражаются с помощью различных языковых средств в зависимости от языковой системы, сложившейся в тои или ином языке для выражения количественных значений. Результаты проведенного исследования относительно изученной темы показали, что в современном русском языке для выражения количественной приблизительности используются следующие языковые средства, включая использование в речи лексических языковых средств аппроксимативности, употребление некоторых предлогов, фразеологизированные конструкции, инверсию и изменение порядка слов в количественно-именных словосочетаниях, группы слов с сочиненным союзом 
или без него, а также, в некоторых случаях, употребляются языковые средства, которые образуют так называемую количественную гиперболу, выражающую неточную временную и пространственную приблизительность. В персидском же языке инверсия и изменение порядка слова не используются как языковой способ и средство выражения количественной приблизительности. Более того, в персидском языке вопрос о количественной приблизительности почти не изучен так, как этот вопрос изучен в языкознании русского языка.

\section{Литература}

1- Беляева Е. И. (1990). Достоверность. Микрополе вероятности // Теория функииональной грамматики. Темпоральность. Модальность. - Л., - С. 157170.

2- Бодуэн де Куртенэ И. А. (1963). Количественность в языковом мышлении: Избранные труды по общему языкознанию. - М., - Т.2.

3- Вежбицкая А. (1999). Семантические универсалии и описание языков, - М.: Издательский дом "ЯСК", - 780 с.

4- Галич Г.Г. (2002). Когнитивная категория количества, Омск: «Омский государственный университет».

5- Есперсен О. (1958). Философия грамматики. - М.: «Издательство иностранной литературы».

6- Золотова Г. А. (1988). Синтаксический словарь: репертуар элементарных единии русского синтаксиса. - М.: «Наука».

7- Маслов Ю.С. (2004). Избранные труды: Аспектология. Общее языкознание, М.: «Языки славянской культуры». 840 с.

8- Мечковская Н.Б. (2005) Постсоветский русский язык: новые черты в соичиолингвистическом статусе // Russian Linguistics, vol. 29, № 1. С. 449-452.

9- Подлесская В.И. Стародубцев а А.В. (2013). О грамматике средств выражения нечеткой номиначии в живой речи. ВЯ. - М.: «Вопросы языкознания».

10- Реформатский А. А. (1987). Лингвистика и поэтика. - М.: «Наука».

11- Рубинчик Ю.А. (2001). Грамматика современного персидского литературного языка. - М.: «Восточная литература» РАН. 
12- Тошович Б. (2005). Квантитативная категоризаџия и категориальная квантификация. Логический анализ языка - Квантификативный аспект языка. - М.: «Индрик».

13- Урысон В. В. (1997). Новый объяснительный словарь синонимов русского языка. - М.: «Языки славянской культуры».

14- Чеснокова Л.Д. (1997). Имя числительное в современном русском языке: Семантика. Грамматика. Функици. Ростов-на-Дону: «Гефест».

15- Широкова Е.Н. (2010). Темпоральный код языка и его эмотивный субкод. Нижний Новгород: «Нижегородский гос. пед. ун-т».

16- Янко Т.Е. (2008). Интонаичинные стратегии русской речи $в$ сопоставительном аспекте. - М.: «Языки славянских культур».

\section{Bibliography}

1- Beljaeva E. I. (1990). Dostovernost'. Mikropole verojatnosti // Teorija funkcional'noj grammatiki. Temporal'nost'. Modal'nost'. - L., - S. 157-170.

2- Bodujen de Kurtenje I. A. (1963). Kolichestvennost' $v$ jazykovom myshlenii: Izbrannye trudy po obshhemu jazykoznaniju. - M., - T.2.

3- Vezhbickaja A. (1999). Semanticheskie universalii $i$ opisanie jazykov, - M.: Izdatel'skij dom "JaSK", - $780 \mathrm{~s}$.

4- Galich G.G. (2002). Kognitivnaja kategorija kolichestva, Omsk: «Omskij gosudarstvennyj universitet».

5- Espersen O. (1958). Filosofija grammatiki. - M.: «Izdatel'stvo inostrannoj literatury».

6- Zolotova G. A. (1988). Sintaksicheskij slovar': repertuar jelementarnyh edinic russkogo sintaksisa. - M.: «Nauka».

7- Maslov Ju.S. (2004). Izbrannye trudy: Aspektologija. Obshhee jazykoznanie, - M.: «Jazyki slavjanskoj kul'tury». $840 \mathrm{~s}$.

8- Mechkovskaja N.B. (2005) Postsovetskij russkij jazyk: novye cherty $v$ sociolingvisticheskom statuse // Russian Linguistics, vol. 29, № 1. S. 449-452.

9- Podlesskaja V. I. Starodubcev a A.V. (2013). O grammatike sredstv vyrazhenija nechetkoj nominacii v zhivoj rechi. VJa. - M.: «Voprosy jazykoznanija».

10- Reformatskij A. A. (1987). Lingvistika i pojetika. - M.: «Nauka».

11- Rubinchik Ju. A. (2001). Grammatika sovremennogo persidskogo literaturnogo jazyka. - M.: «Vostochnaja literatura» RAN. 
12- Toshovich B. (2005). Kvantitativnaja kategorizacija $i$ kategorial'naja kvantifikacija. Logicheskij analiz jazyka - Kvantifikativnyj aspekt jazyka. - M.: «Indrik».

13- Uryson V. V. (1997). Novyj ob\#jasnitel'nyj slovar' sinonimov russkogo jazyka. M.: «Jazyki slavjanskoj kul'tury».

14- Chesnokova L. D. (1997). Imja chislitel'noe v sovremennom russkom jazyke: Semantika. Grammatika. Funkcii. Rostov-na-Donu: «Gefest».

15- Shirokova E. N. (2010). Temporal'nyj kod jazyka i ego jemotivnyj subkod. Nizhnij Novgorod: «Nizhegorodskij gos. ped. un-t».

16- Janko T. E. (2008). Intonacionnye strategii russkoj rechi v sopostavitel'nom aspekte. - M.: «Jazyki slavjanskih kul'tur».

HOW TO CITE THIS ARTICLE

Хасан-заде, Р. (2021). Methods for Expressing the Category of Approximation in Russian in Comparison with Its Equivalents in Persian. Issledovatel'skiy Zhurnal Russkogo Yazyka I Literatury, 9(1). 201-219.

DOI: $10.52547 /$ iarll.17.201

URL: https://www.journaliarll.ir/index.php/iarll/article/view/135

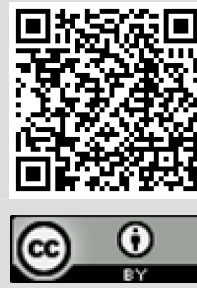




\section{روشهاى بيان مفاهيم تقريبى در زبان روسى در مقايسه با معادلهاى آنها در زبان فارسى}

$$
\begin{aligned}
& \text { رضوان حسنزاده' } \\
& \text { استاديار كروه زبان و ادبيات روسى و اسلاوى دانشخاه شهيد بهشتى، راده }
\end{aligned}
$$

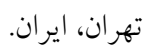

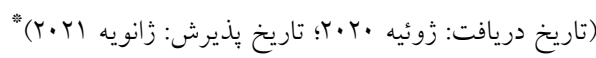

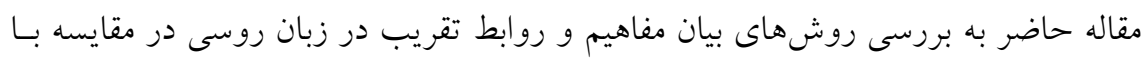

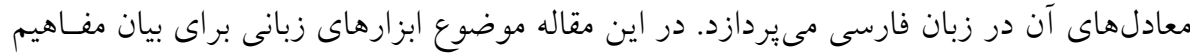

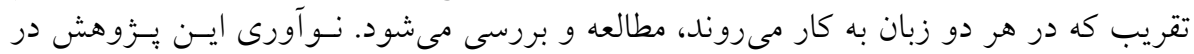

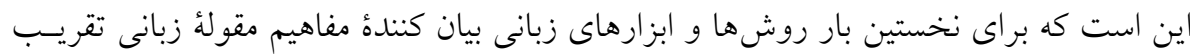

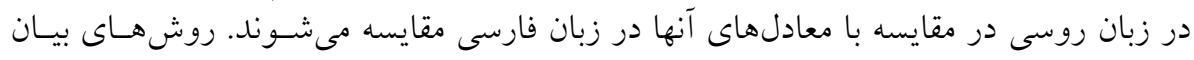

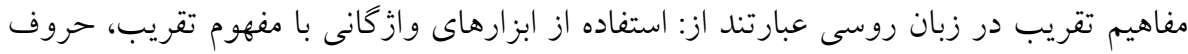

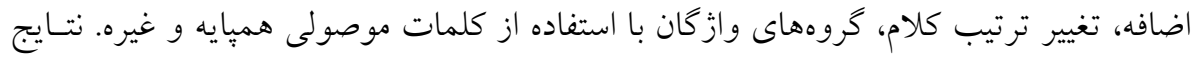

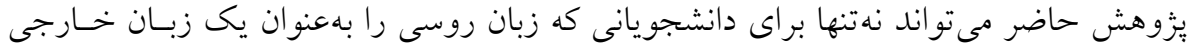

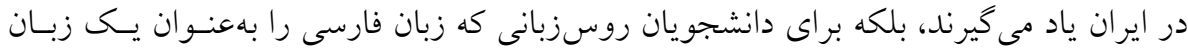

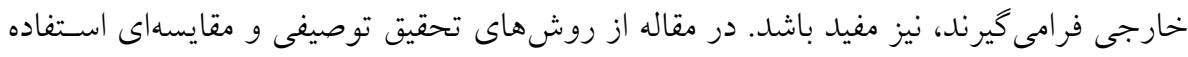

وازگًان كليدى: مفهوم مقدار، مقوله تقريب، مفاهيم مقدار و كميت، زبان روسى، زبان فارسى،

تحليل مقايسهاى.

1. E-mail: re_hassanzadeh@sbu.ac.ir

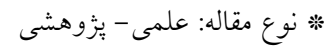

